\title{
Effects of Crop Stubble on Physicochemical Properties of Continuous Cropping Soil and Cucumber Yield and Quality
}

\author{
Yuyan Wang ${ }^{1,2}$, Zhongwei Wang ${ }^{1 *}$, Guichun Yang ${ }^{1}$, Li Wang ${ }^{1}$, Yi Zheng ${ }^{1}$ \\ ${ }^{1}$ Institute of Economic Botany, Jilin Academy of Agricultural Sciences, Gongzhuling, China; ${ }^{2}$ Eco-Agriculture Research Center, \\ Binzhou Vocational College, Binzhou, China. \\ Email: *13756127666@163.com
}

Received May 29 ${ }^{\text {th }}$, 2012; revised August $3^{\text {rd }}, 2012$; accepted August $14^{\text {th }}, 2012$

\begin{abstract}
By a pot experiment, two kinds of crop stubble (wheat, soybean) were added into continuous cropping soil of cucumber according to different quantity $(0.5 \%, 1 \%$ and $2 \%)$, the effects of different kinds of stubble and quantity on the continuous cropping soil and growth of cucumber were investigated. The results showed that two kinds of crop stubble significantly decreased soil bulk density, and increased total porosity of soil. Each of all treatments significantly decreased the accumulation of salinity in soil within the entire growth period of cucumber. $2 \%$ wheat stubble treatment had the biggest drop in soil EC in the later period of cucumber growth. Soybean stubble treatment had the lesser effect on soil EC. Wheat and soybean stubble promoted the growth of cucumber, increased the yield of cucumber, and improved the quality of cucumber. $2 \%$ of wheat stubble treatment had a biggest increase in cucumber yield, which increased the yield by $34.23 \%$ compared with the control.
\end{abstract}

Keywords: Wheat; Soybean; Stubble; Continuous Cropping Cucumber; Sick Soil; Yield and Quality; Physicochemical Properties

\section{Introduction}

Along with the continuous development of protected vegetables, it is increasingly common that the same kind of vegetable was continuously grown in the same piece of land, so, the soil diseases in protected vegetables cultivation becomes more and more severe [1]. A number of vegetables in protected cultivation such as cucumber, tomato, eggplants, pepper and so on have frequently suffered continuous cropping obstacles, the continuous cropping obstacle often caused these plants weak growth, inferior fruit quality and special soil diseases [2,3]. The cucumber is one of the main types to be cultivated in protected vegetables, and it is even extremely intolerant to continuous cropping. Therefore, the continuous cropping obstacles of cucumber is more severe, which has already become one of the major factors for restricting the yield and quality of protected cucumber. Thus, it is imminent to solve the problem of continuous cropping obstacle of protected cucumber.

In order to explore the effective ways and measures to overcome or reduce continuous cropping obstacle of pro-

\footnotetext{
"Corresponding author.
}

tected vegetables, agricultural experts had contributed a lot of research work. Currently there are three kinds of remediation technologies including physical, chemical and bioremediation to continuous cropping soils [4]. However, these technologies all have certain limitations. Some studies showed that organic materials could improve the physicochemical properties of continuous cropping soil, increase the diversity of microbial community structure in soil, inhibit the reproduction of pathogenic microorganisms in soil, and reduce the accumulation of toxic substances in soil [5]. For example, straw returning had very good effects for improving and cultivating the sick soil [6], the application of straw mixed with biopreparate could improve the continuous cropping soils in greenhouse, even could promote the growth and development of vegetable [7]. In order to discover more effective ways and measures for overcoming or reducing continuous cropping obstacle of protected vegetables, we placed two kinds of crushed crop stubble (wheat and soybean) into the soil of continuous cropping cucumber for study. Currently, the studies of effect of wheat, soybean stubble on the continuous cropping obstacle of cucumber have not been reported. At the same time, the straw and stubble are waste in farmland, if which are 
used for improving the continuous cropping soil, the resources will be saved, and environmental pollution will be reduced. Therefore, this study has great applicated value and theoretical significance.

In addition, because the allelopathy is ubiquitous in crops, and it has significant effect on seed germination and crop growth [8], so the types of stubble to be used for improving continuous cropping soil of cucumber should be strictly selected. Meanwhile, the consumption of stubble adding, the methods of stubble adding and other issues all need to be further studied. To this end, in this study, we selected two kinds of crops stubble (wheat and soybean) and placed them into continuous cropping soils of cucumber in greenhouse to study the effect of the crops stubble on the continuous cropping soils and cucumber growth, so that we can provide scientific basis and technical methods for solving the problem of continuous cropping obstacles in protected vegetables.

\section{Materials and Methods}

\subsection{Experimental Materials}

Wheat (Triticum aeslivum L.) variety: Kefeng No. 6, soybean (Glycine max) variety: North 86-4, cucumber (Cucumis sativus L.) variety: Tianjin Green No. 3.

The tested stubble: Wheat and soybean stubble were obtained from the residues of previous crops harvested, including the roots. When the crops stubble was collected, firstly, the stubble was dug from soil, and then cleaned, dried, and crushed by the grinder [8]. The physicochemi- cal properties of the crops stubble were as shown in the following table (Table 1).

The tested soil: the sampled soil was taken from continuous cropping soil of cucumber in greenhouse, the basic physicochemical properties of the sampled soil prior the experiment were as shown in the following table (Table 2).

\subsection{Pot Study}

Here, studies were done in pots in March to August, 2009.

The diameter of pot was $30 \mathrm{~cm}, 22 \mathrm{~cm}$ high, loading 8 $\mathrm{kg}$ of soil per pot. First, the soil of continuous cropping cucumber was sieved through $6 \mathrm{~mm}$ sieve to remove larger clods and the other plant residues etc. Second, the sieved soils and crushed stubble were uniformly mixed together according to the different weight ratio (Table 3 ). Third, we placed the mixed soils into pots ( $8 \mathrm{~kg}$ per $30 \times$ $22 \mathrm{~cm}$ pot). Then, these pots were adequately watered, covered by plastic film to decompose for 21 days in solar greenhouse. To release some of harmful gases, the plastic film had been removed for a week when cucumber seedlings were planted. The pots were placed on ground in solar greenhouse as $60 \times 30 \mathrm{~cm}$, and $5 \mathrm{~g}$ diammonium phosphate was put into per pot, cucumber seedlings were planted after three days. The pots without stubble were used as the controls (CK).

The experiment included a total of 7 treatments ( 2 kinds of stubble $\times 3$ kinds of dosage +1 control). And these treatments were repeated 3 times, we used 30 pots for each treatment, making a total of 630 pots.

Table 1. Physicochemical properties of the tested stubble.

\begin{tabular}{|c|c|c|c|c|c|}
\hline $\begin{array}{l}\text { Tested } \\
\text { stubble }\end{array}$ & $\begin{array}{c}\text { Total } \\
\text { carbon }\left(\mathrm{mg} \cdot \mathrm{g}^{-1}\right)\end{array}$ & $\begin{array}{l}\text { Total nitrogen } \\
\left(\mathrm{mg} \cdot \mathrm{g}^{-1}\right)\end{array}$ & $\begin{array}{l}\text { Total phosphorus } \\
\left(\mathrm{mg} \cdot \mathrm{g}^{-1}\right)\end{array}$ & $\begin{array}{l}\text { Total potassium } \\
\quad\left(\mathrm{mg} \cdot \mathrm{g}^{-1}\right)\end{array}$ & $\mathrm{C} / \mathrm{N}$ \\
\hline Wheat & 328.57 & 7.38 & 1.71 & 9.52 & 83.63 \\
\hline Soybean & 284.67 & 9.36 & 1.35 & 3.54 & 49.27 \\
\hline
\end{tabular}

Table 2. Physicochemical properties of the tested soils.

\begin{tabular}{|c|c|c|c|c|c|c|c|c|}
\hline $\begin{array}{l}\text { Total } \\
\text { nitrogen } \\
\left(\mathrm{g} \cdot \mathrm{kg}^{-1}\right)\end{array}$ & $\begin{array}{c}\text { Alkalihydrolysible } \\
\mathrm{N} \\
\left(\mathrm{mg} \cdot \mathrm{kg}^{-1}\right)\end{array}$ & $\begin{array}{l}\text { Total } \\
\text { hosphorus } \\
\left(\mathrm{g} \cdot \mathrm{kg}^{-1}\right)\end{array}$ & $\begin{array}{l}\text { Quick acting P } \\
\left(\mathrm{g} \cdot \mathrm{kg}^{-1}\right)\end{array}$ & $\begin{array}{l}\text { Total } \\
\text { potassium } \\
\left(\mathrm{g} \cdot \mathrm{kg}^{-1}\right)\end{array}$ & $\begin{array}{l}\text { Quick acting } \\
\mathrm{K} \\
\left(\mathrm{g} \cdot \mathrm{kg}^{-1}\right)\end{array}$ & $\begin{array}{l}\text { Organic } \\
\text { matte } \\
(\%)\end{array}$ & $\mathrm{pH}$ & $\begin{array}{c}\mathrm{EC} \\
\left(\mathrm{ms} \cdot \mathrm{cm}^{-1}\right)\end{array}$ \\
\hline 2.67 & 0.292 & 1.63 & 0.269 & 1.16 & 0.327 & 1.56 & 7.66 & 1.61 \\
\hline
\end{tabular}

Table 3. The Symbols used for different stubble and quantity.

\begin{tabular}{|c|c|c|c|c|c|c|c|}
\hline Stubble & \multicolumn{3}{|c|}{ Wheat } & \multicolumn{3}{|c|}{ Soybean } & \multirow{2}{*}{$\begin{array}{c}\text { Contro } \\
0\end{array}$} \\
\hline Adding quantity & $0.5 \%$ & $1 \%$ & $2 \%$ & $0.5 \%$ & $1 \%$ & $2 \%$ & \\
\hline Symbol & A1 & A2 & A3 & B1 & B2 & B3 & $\mathrm{CK}$ \\
\hline
\end{tabular}




\subsection{Sampling and Determination}

Sampling: We sampled one time per 20 days after the cucumber seedlings planting, making a total of 3 times. We randomly selected 3 pots to collect rhizosphere soil each time, the topsoil in the vicinity of the cucumber plants was removed before collecting rhizosphere soil. The soil samples of 3 replications were collected respectively, then mixed, sieved through $2 \mathrm{~mm}$ sieve. The soil samples were air-dried for storage, which were used for determining physicochemical indicators of the continuous cropping soil and soil enzyme activity.

Soil indicators: Soil $\mathrm{pH}$ was determined using the PHS-2F digital $\mathrm{pH}$ meter, Soil EC by using DDS-11A conductivity, the soil bulk density by using cutting ring, total porosity of soil was calculated by soil bulk density $(r)$ and soil proportion $(d)$, the formula is as follows:

$$
p_{1}=[1-(r / d)] \times 100 \% .
$$

The soil density was replaced by the mean value of general soil, taking $2.65\left(\mathrm{~g} / \mathrm{cm}^{3}\right)$. The soil moisture was determined using drying weight method, the formula is as follows:

Soil moisture $(\%)=\left(W_{1}-W_{2}\right) /\left(W_{2}-W\right) \times 100 \%[9,10]$.

Cucumber yield: Five plants were chosen arbitrarily in each treatment, and were marked. We recorded yield of each plant singly, took their average, and then converted it into the yield of per hectare $\left(\mathrm{hm}^{2}\right)$.

Cucumber quality: Soluble solids were determined using hand-held sugar meter (Made in Japan), Vc content by using 2,6-dichlorophenol indophenol titration. Taste was evaluated by using sensory identification method.

\section{Results}

\subsection{Physicochemical Properties of Soil}

\subsubsection{Bulk Density and Porosity}

Wheat and soybean stubble decreased the bulk density of soil, and increased soil porosity (Table 4). All wheat stubble treatments decreased significantly bulk density of soil, moreover, the bulk density constantly decreased as the increase of wheat stubble quantity. A2 and A3 had the larger reduction, but there was no significant difference between the A2 and A3. Soybean stubble had also similar effect, but the effect of soybean stubble was smaller than that of wheat stubble. This shows that two kinds of crop stubble help to decrease bulk density of soil, and increase the soil permeability. However, each of stubble treatments had contrary result on the porosity of soil. All treatments increased the porosity of soil, moreover, the porosity constantly increased as the increase of stubble quantity. $2 \%$ wheat stubble had a greatest effect on the porosity of soil, increasing by $24.4 \%$ than the control, and followed by $2 \%$ soybean stubble, increasing by $18.96 \%$.

\subsubsection{Soil Moisture}

Two kinds of crop stubble had certain effect on soil $\mathrm{pH}$, but the effect was different in different growth periods (Figure 1). In the pre-stage of cucumber growth, two kinds of stubble increased the moisture of soil, wheat stubble had greater effect on the moisture of soil compared with soybean stubble. The greatest effect was observed in $2 \%$ wheat stubble treatment, which increased the moisture by $26.37 \%$ compared with control. Soybean stubble treatments had similar effects, but these effects were smaller, in particular, $0.5 \%$ soybean stubble had a minimum effect, which had no difference compared with the control.

In the medium term, wheat stubble treatment increased largely the moisture of soil, $2 \%$ of wheat stubble had greatest affect on the moisture, which was significantly higher than other treatments and control, increased by $34.35 \%$ than control. Soybean stubble treatment had also similar effects, $2 \%$ of soybean stubble treatment had greatest affect on the moisture.

In the later period, all treatments increased the soil moisture too, but these treatments had lesser increase in soil moisture.

Table 4. Effect of different treatments on bulk density and porosity of soil.

\begin{tabular}{ccc}
\hline Treatments & Bulk density $\left(\mathrm{g} \cdot \mathrm{cm}^{-3}\right)$ & Total porosity (\%) \\
\hline A1 & $1.21 \pm 0.08 \mathrm{bc}$ & $54.34 \pm 6.16 \mathrm{c}$ \\
A2 & $1.02 \pm 0.08 \mathrm{~d}$ & $58.51 \pm 8.02 \mathrm{~b}$ \\
A3 & $1.01 \pm 0.06 \mathrm{~d}$ & $61.89 \pm 6.33 \mathrm{a}$ \\
B1 & $1.26 \pm 0.05 \mathrm{~b}$ & $52.45 \pm 4.61 \mathrm{~cd}$ \\
B2 & $1.16 \pm 0.07 \mathrm{c}$ & $56.23 \pm 7.12 \mathrm{bc}$ \\
B3 & $1.12 \pm 0.03 \mathrm{c}$ & $57.74 \pm 3.13 \mathrm{~b}$ \\
CK & $1.41 \pm 0.08 \mathrm{a}$ & $46.79 \pm 5.18 \mathrm{e}$ \\
\hline
\end{tabular}

Note: Values are means \pm standard deviation. Significant differences $(\mathrm{P}<0.05$ using Duncan’s multiple range test) among treatments in the same column are indicated by different letters, the same as below. 




Figure 1. Effect of different treatments on moisture of soil.

\subsubsection{Soil pH}

Two kinds of stubble had certain effect on soil $\mathrm{pH}$, but the effect was relatively smaller (Table 5). In the prestage and mid of growth, most of the stubble treatments decreased soil $\mathrm{pH}$, only the $2 \%$ wheat stubble (A3) increased it. $2 \%$ wheat stubble treatment had the greatest increase in the soil $\mathrm{pH}$, but there was significant difference between it and control. Other treatments had no significant difference too.

In the later stage of growth, all stubble treatments decreased soil $\mathrm{pH}$ but only $2 \%$ wheat stubble treatment increased it. 2\% wheat stubble treatment was significantly higher than control, while other treatments had on significant difference compared with control. The maximum decrease was observed in the $1 \%$ soybean stubble treatment, but it had on significant difference compared with control.

\subsubsection{Soil EC}

Two kinds of stubble had relatively larger effect on soil EC (Table 6). In the pre-stage of cucumber growth, all wheat stubble treatments significantly decreased soil EC, a maximum decrease was observed in $1 \%$ wheat stubble treatment, and followed by $0.5 \%$ wheat stubble treatment. Soybean stubble also decreased soil EC, the soil EC values of all soybean stubble treatments were significantly lower than the control, $0.5 \%$ and $1 \%$ of soybean stubble had greater decrease in soil EC. In the mid-and late, whether wheat stubble or soybean stubble all showed the similar laws in soil EC.

\subsection{Cucumber Yield}

Two kinds of stubble increased yield of cucumber (Figure 2). All treatments of wheat stubble markedly increased yield of cucumber, the highest yield was observed in $2 \%$ wheat stubble treatment, which increased the yield by $34.23 \%$ compared with control. Soybean stubble increased yield of cucumber too, but soybean stubble treatment had the smaller increase than wheat stubble treatment. The higher yield was observed in $1 \%$ soybean stubble treatment, which increased the yield by $16.01 \%$ compared with control.
Table 5. Effect of different treatments on soil $\mathrm{pH}$ after planting.

\begin{tabular}{cccc}
\hline Treatments & 20 days & 40 days & 60 days \\
\hline A1 & $7.35 \pm 0.04 \mathrm{ab}$ & $7.35 \pm 0.08 \mathrm{ab}$ & $7.33 \pm 0.16 \mathrm{bc}$ \\
A2 & $7.34 \pm 0.14 \mathrm{ab}$ & $7.47 \pm 0.17 \mathrm{ab}$ & $7.27 \pm 0.14 \mathrm{bc}$ \\
A3 & $7.77 \pm 0.16 \mathrm{a}$ & $7.73 \pm 0.06 \mathrm{a}$ & $7.66 \pm 0.05 \mathrm{a}$ \\
B1 & $7.62 \pm 0.06 \mathrm{a}$ & $7.38 \pm 0.03 \mathrm{ab}$ & $7.34 \pm 0.05 \mathrm{bc}$ \\
B2 & $7.41 \pm 0.12 \mathrm{ab}$ & $7.35 \pm 0.05 \mathrm{ab}$ & $7.26 \pm 0.03 \mathrm{bc}$ \\
B3 & $7.21 \pm 0.09 \mathrm{~b}$ & $7.30 \pm 0.06 \mathrm{ab}$ & $7.28 \pm 0.08 \mathrm{bc}$ \\
CK & $7.61 \pm 0.08 \mathrm{a}$ & $7.65 \pm 0.11 \mathrm{a}$ & $7.49 \pm 0.11 \mathrm{~b}$ \\
\hline
\end{tabular}

Table 6. Effect of different treatments on soil EC after planting (ms/cm).

\begin{tabular}{cccc}
\hline Treatments & 20 days & 40 days & 60 days \\
\hline A1 & $0.79 \pm 0.04 \mathrm{f}$ & $1.07 \pm 0.06 \mathrm{e}$ & $0.82 \pm 0.03 \mathrm{f}$ \\
A2 & $0.73 \pm 0.07 \mathrm{~cd}$ & $1.04 \pm 0.07 \mathrm{e}$ & $0.88 \pm 0.06 \mathrm{ef}$ \\
A3 & $0.97 \pm 0.02 \mathrm{e}$ & $1.01 \pm 0.04 \mathrm{e}$ & $0.80 \pm 0.06 \mathrm{f}$ \\
B1 & $1.14 \pm 0.09 \mathrm{c}$ & $1.13 \pm 0.06 \mathrm{~d}$ & $0.93 \pm 0.08 \mathrm{e}$ \\
B2 & $1.16 \pm 0.07 \mathrm{c}$ & $1.16 \pm 0.05 \mathrm{~d}$ & $1.38 \pm 0.03 \mathrm{~b}$ \\
B3 & $1.24 \pm 0.08 \mathrm{~b}$ & $1.37 \pm 0.09 \mathrm{c}$ & $1.25 \pm 0.04 \mathrm{c}$ \\
CK & $1.62 \pm 0.03 \mathrm{a}$ & $1.72 \pm 0.01 \mathrm{a}$ & $1.66 \pm 0.05 \mathrm{a}$ \\
\hline
\end{tabular}

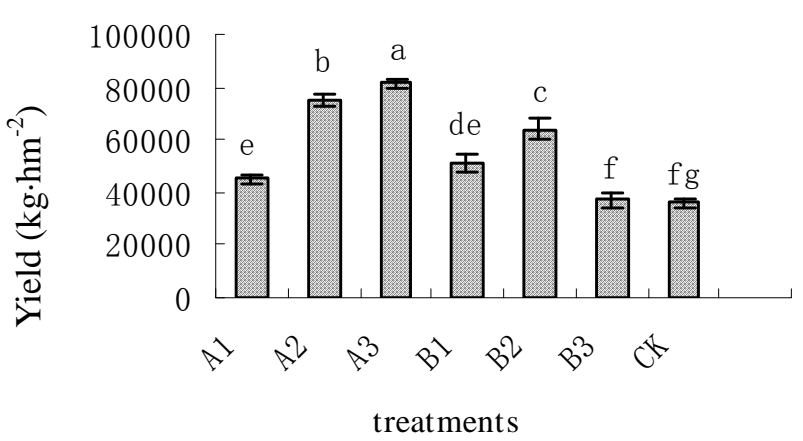

Figure 2. Effect of different treatments on the yield of cucumber. 


\subsection{Cucumber Quality}

As can be seen from Table 7, wheat stubble significantly improved cucumber quality. First, wheat stubble increased the content of dry matter, moreover, the content of dry matter gradually increased as the increase of wheat stubble quantity. Second, wheat stubble increased the content of vitamin $\mathrm{C}$ and soluble solids in fruits, but $0.5 \%$ wheat stubble treatment had no difference compared with the control. Third, wheat stubble decreased the incidence of deformed fruits. The greatest decrease was observed in $2 \%$ wheat stubble treatment, and followed by $1 \%$ wheat stubble treatment.

Soybean stubble had certain effect in improving fruit quality too. $0.5 \%$ and $1 \%$ of soybean stubble treatments increased the content of dry matter, while an opposite result was observed in $2 \%$ of treatment. Soybean stubble had no obvious regularity on the content of vitamin $C$ and soluble solids in fruits, which was sometimes ascending and sometimes descending. $0.5 \%$ of soybean stubble treatment significantly increased the content of vitamin $\mathrm{C}$ in fruits, but it had a little effect on the soluble solids. $2 \%$ of soybean stubble treatment decreased the incidence of deformed fruits, which was significantly lower than control.

\section{Conclusions}

Many studies showed that organic materials decreased soil bulk density, increased total porosity, increased soil aggregate structure, and improved soil permeability when they were added into soil $[9,10]$. At the same time, organic materials could increase soil $\mathrm{pH}$, and lower soil EC, even that they could improve the physicochemical properties [11,12].

In this test, whether wheat stubble or soybean stubble obviously decreased soil EC, especially in the later period, the decrease of soil EC was greater. Each of all treatments significantly decreased the salinity accumula- tion in soil within the entire growth period of cucumber, a maximum decrease of the EC was observed in $2 \%$ wheat stubble treatment, while effect of two kinds of stubble on soil $\mathrm{pH}$ was not obvious. This may be related to the microbial metabolism, because the stubble can provide more nutrients for the microorganisms in soil, and promote the activity of microorganisms. Thus, wheat or soybean stubble can reduce continuous cropping obstacle in greenhouse soil. For example, when two kinds of stubble are added into the continuous cropping soil, many of the problems such as soil compaction, stalinization, poor permeability and poor water holding capacity, even some soil sickness will be solved. Therefore, wheat stubble or soybean stubble has a positive effect in promoting cucumber growth and improving sick soil.

Soil moisture is an important indicator related to soil microorganism activity and crop growth, which directly affects the growth and yied of crops. According to research report $[13,14]$, straw returning enhanced the abilities for soil to retain water and nutrients, increase capacity of holding water, and improve the effectiveness of natural precipitation. Wang [15] (2000) studied the effects of straw for different processing methods on soil moisture, the results showed that straw returning improved soil moisture conditions, increased the capacity of water storage and water retention in soil.

In this test, the results showed that two kinds of stubble increased soil moisture, while the effect of wheat stubble on soil moisture was greater than that of soybean stubble, and $2 \%$ of wheat stubble had greatest effect, which increased soil moisture by $26.37 \%$ compared with control. One of the main reasons is that the density of wheat stubble is smaller than that of soybean stubble, so the volume of wheat stubble is relatively larger than that of soybean stubble. Therefore, wheat stubble treatment has greater increase on soil total porosity than soybean stubble, so wheat stubble is more conducive to increase the soil moisture. In addition, because the density of

Table 7. Effect of different treatments on the quality of cucumber.

\begin{tabular}{|c|c|c|c|c|c|}
\hline Treatment & Deformed fruits rate (\%) & $\begin{array}{l}\text { Dry matter } \\
(\%)\end{array}$ & $\begin{array}{c}\text { Vitamin C } \\
(\mathrm{mg} / 100 \mathrm{~g} \mathrm{FW})\end{array}$ & Soluble solids (\%) & Taste \\
\hline A2 & $6.33 \pm 0.08 \mathrm{e}$ & $3.84 \pm 0.06 b$ & $12.23 \pm 0.13 b$ & $9.1 \pm 0.09 a$ & Excellent \\
\hline B1 & $9.01 \pm 0.16 c$ & $3.33 \pm 0.10 c$ & $12.37 \pm 0.18 b$ & $8.1 \pm 0.12 b$ & Good \\
\hline B2 & $8.33 \pm 0.06 \mathrm{~d}$ & $3.37 \pm 0.04 \mathrm{c}$ & $10.58 \pm 0.12 d$ & $7.9 \pm 0.07 b$ & Excellent \\
\hline B3 & $11.28 \pm 0.09 a$ & $2.26 \pm 0.06 \mathrm{ef}$ & $10.59 \pm 0.11 d$ & $7.5 \pm 0.10 \mathrm{~d}$ & Good \\
\hline CK & $9.67 \pm 0.11 c$ & $2.63 \pm 0.07 \mathrm{e}$ & $9.66 \pm 0.07 \mathrm{e}$ & $7.8 \pm 0.11 d$ & General \\
\hline
\end{tabular}


wheat stubble is smaller than that of soybean stubble, so more wheat stubble was floated on the water when watering, and it was just attached to the soil surface after the water seeping down, thus wheat stubble treatment can decrease water evaporation, and relatively increase the soil moisture. This may be another reason that the wheat stubble is more conducive to increase the soil moisture.

According to studies, there are three major reasons on continuous cropping obstacle of cucumber: First, the nutrients in soil were in imbalance, the physicochemical properties of soil became worse. Second, the pathogens in soil proliferated quickly, the ecological environments of microorganisms were destroyed, and the biological properties of soil became worse. Third, it is due to the allelopathy of the root exudates and the stubble decomposition $[5,16,17]$. It is exactly effective ways and measures for Mixed intercropping, crop rotation and the development and application of soil remediation agents to solve this problem. According to the investigation, straw return can promote the growth of crops, increase crop yields by $5 \%-10 \%[18,19]$. According to another report, organic material also can increase cucumber yields when it was added into soil in the greenhouse $[4,20]$. In our experiment, wheat and soybean stubble promoted the growth of cucumber, increased yield of cucumber. Among, $1 \%$ and $2 \%$ of wheat stubble markedly increased yield of cucumber, the highest increase of yield was observed in $2 \%$ wheat stubble treatment, which increased the yield by $34.23 \%$ compared with control. Thus, two kinds of crop stubble can coordinate the water, gas, heat, nutrient and other conditions in soil, improve the physicochemical properties of soil. So, this helps to establish a good foundation for cucumber growth and yield increase. In our experiment, the wheat and soybean stubble increased soil moisture, this may be one of the important reasons which caused the increase of cucumber growth and yield.

\section{Conclusion}

Wheat and soybean stubble all obviously decreased the soil EC, while the effect of two kinds of stubble on soil $\mathrm{pH}$ was not obvious. Two kinds of stubble increased soil moisture and porosity, in which the effect of wheat stubble was more remarkable than that of soybean stubble. At the same time, wheat and soybean stubble promoted the growth of cucumber, increased the yield of cucumber, and improved the quality of cucumber. This shows that wheat and soybean stubble can improve the physicochemical properties in continuous cropping soil, and reduce continuous cropping obstacles of cucumber.

\section{Acknowledgements}

This project was financially supported by Introducing Innovation Talent Fund of Jilin Province. Here, I express my heartfelt thanks for them.

\section{REFERENCES}

[1] Z. Z. Li, Y. Wu and Y. J. Yang, "Effects of Soil Conditioners on Cucumber Growth and Soil Conditions in Greenhouse,” Acta Agriculture Shanghai, Vol. 27, No. 2, 2011, pp. 87-91.

[2] J. Liu, Y. Q. Tian and L. H. Gao, "Effects of Summer Catch Crop and Straw Returning on Cucumber Soil Nutrients and Microorganism in Solar Energy Greenhouse," China Vegetables, Vol. 6, No. 8, 2011, pp. 12-16.

[3] H. Q. Wu, L. L. Dong and Q. Wang, "Effects of Garlicon Cucumber Growth and Soil Biology in Solar Greenhouse,” Journal of China Agricultural University, Vol. 16, No. 3, 2011, pp. 95-99.

[4] M. Yang, L. J. Yang and Q. Chang, "Effect of Different Straw Reapplication on Yields of Cucumber and Soil Fertility,” Northern Horticulture, Vol. 6, 2011, pp. 46- 48.

[5] Z. Q. Gao and S. X. Zhang, "Continuous Cropping Obstacle and Rhizospheric Microecology I. Root Exudates and Their Ecological Effects," Chinese Journal of Applied Ecology, Vol. 9, No. 5, 1998, pp. 549-554.

[6] Z. J. Wu, H. J. Zhang and G. S. Xu, "Effect of Returning Corn Straw into Soil on Soil Fertility,” Chinese Journal of Applied Ecology, Vol. 13, No. 5, 2002, pp. 539-542.

[7] Z. D. Yu and S. Y. Song, "Effects of Straw Mixed with Biopreparate on Improvement of Soil in Greenhouse," Chinese Society of Agricultural Engine, Vol. 19, No. 1, 2003, pp. 177-179.

[8] Y. Y. Wang and F. Z. Wu, "Allelopathic Effects of Wheat, Soybean and Oat Residues on Cucumber and Fusarium oxysporum f. sp. cucumerinum Owen,” Allelopathy Journal, Vol. 25, No. 1, 2010, pp. 107-114.

[9] J. Wu, Z. L. Zhu and J. G. Zheng, "Effect of Straw Returing Covering on Physical and Chemical Properties of Soil and Crop Yield,” Journal of Southwest Agricultural University, Vol. 19, No. 2, 2006, pp. 192-195.

[10] L. Zhu, C.-L. Zhang and Q. R. Shen, "The Influence of Appling Organic Materials in the Continuous Cropping Soil on the Soil pH and EC Value and Microbe,” Journal of Anhui Agricultural University, Vol. 28, No. 4, 2001, pp. 350-353.

[11] X. F. Zhou, Y. H. Xie and Y. H. Pei, "Effect of Adding Straw Powder on the Physical and Chemical Properties of Saline Alkali Soil,” Hubei Agricultural Sciences, Vol. 50, No. 23, 2011, pp. 4806-4808.

[12] E. Ouedraogo, A. Mando and N. P. Zombre, "Use of Compost to Improve Soil Properties and Crop Productivity under Low Input Agricultural System in West Africa,” Agriculture Ecosystems and Environment, Vol. 84, No. 3, 2001, pp. 259-266. doi:10.1016/S0167-8809(00)00246-2

[13] Z. X. Zhu and T. X. Liu, "Research Progress of Ecological Effect of Straw Returning,” Anhui Agricultural Sciences, Vol. 35, No. 23, 2007, pp. 7221-7223.

[14] Q. H. Zhan, X. P. Zhang and C. L. Yuan, "Study on the 
Effect of Straw Returning and It's Mechanism in Improving Shajiang Black Soil,” Journal of Anhui Agricultural University, Vol. 29, No. 1, 2002, pp. 53-59.

[15] A. L. Wang, W. S. Gao and J. Y. Huang, "Study on the Ecological Effect of Returning into Soil with Different Methods," Chinese Journal of Agricultural Resources and Regional Planning, Vol. 21, No. 2, 2000, pp. 41-45.

[16] X. He, W. S. Wei and R. G. Sun, "Effect of Straw-Bentonite-PAM Improved Material on Saturated Water Content in Sandy Soil," Chinese Agricultural Science Bulletin, Vol. 28, No. 9, 2012, pp. 75-78.

[17] X. Y. Ma and H. M. Wang, “Technology of Crop Stubble Returning to Fields,” Jilin Agricultury, No. 9, 2010, pp. 56-58.
[18] P. Mu, E. H. Zhang and H. N. Wang, "Effects of Continuous Straw Return to Soil on Maize Growth and Soil Chemical and Physical Characteristics," Chinese Journal of Eco-Agriculture, Vol. 20, No. 3, 2012, pp. 291-296. doi:10.3724/SP.J.1011.2012.00291

[19] R. S. Jessop and L. W. Stewart, "Effects of Crop Residues, Soil Type and Temperature on Emergence and Early Growth of Wheat," Plant and Soil, No. 74, No. 1, 1983, pp. 101-109. doi:10.1007/BF02178745

[20] Z. P. Wang, J. R. Yang and C. S. Hu, "The Ways of Efficient Use and Technical Measures of Straw Resources in Taihang Mountain Plain,” Resources Science, Vol. 23, No. 5, 2001, pp. 67-72. 